\title{
An Experimental Investigation into the Thermal Properties of Nano Fluid
}

Tushar A Sinha ${ }^{1 *}$, Amit Kumar ${ }^{1}$, Nikhilesh Bhargava ${ }^{1}$ and Soumya S Mallick ${ }^{2}$

${ }^{1}$ Department of Mechanical Engineering, Thapar University, Patiala 147004, India

${ }^{2}$ Faculty, Department of Mechanical Engineering, Thapar University, Patiala 147004, India

\begin{abstract}
In this paper, the results of the experimental investigation on the thermal properties of Nano fluid are presented. The effect of sonication time, settling time and temperature on the thermal conductivity, viscosity and specific heat of zinc oxide ( $\mathrm{ZnO}, 14 \mathrm{~nm}$ and $25 \mathrm{~nm}$ size) and single walled carbon nanotube (SWCNT, 10nm size) based Nano fluid are investigated and the results of $\mathrm{ZnO}$ with DI water and ethylene glycol (EG) as base fluids are compared. The experimental results indicate that the studied parameters have a remarkable effect on the thermal properties of Nano fluid. The rate of enhancement in thermal conductivity of EG based Nano fluid is found to be less than that of water based Nano fluid. The SWCNT based DI water Nano fluid found to be very unstable i.e. the nanoparticles settle down very rapidly. The $0.02 \%$ volume fraction of SWCNT nanoparticles suspension results in $10 \%$ increase in the specific heat of DI water. A decrement of $24 \%$ and $13 \%$ in the specific heat of $14 \mathrm{~nm}$ size $\mathrm{ZnO}$ based Nano fluid were obtained at a volume fraction of $0.001 \%$ and $0.002 \%$ respectively.
\end{abstract}

Keywords: Nano fluid; Heat transfer; Nanoparticles; Viscometer; Torque meter

\section{Introduction}

Nano fluid came into picture in the field of heat transfer in systems since it was introduced by Choi [1]. The heat transfer coefficient of a fluid depends on thermal properties like conductivity, viscosity and specific heat. So far the effect of particle size, volume fraction and temperature was studied by many researchers [2-5] but the effect of sonication and settling time on Nano fluid is studied by few researchers [6-11]. Calvin [12] investigated effect of volume fraction and temperature on the $\mathrm{CuO}$ and $\mathrm{Al}_{2} \mathrm{O}_{3}$ nanoparticles based water Nano fluid and the results showed an increase of $52 \%$ in the thermal conductivity of DI water, when $\mathrm{CuO}$ nanoparticles were dispersed at a volume fraction of $6 \%$ [13]. Also, an increase of $30 \%$ in the conductivity of $\mathrm{Al}_{2} \mathrm{O}_{3}$ based Nano fluid was reported at volume fraction $10 \%$ in a temperature range of 27.5 to $34.7^{\circ} \mathrm{C}$. Jang [14] investigated the effect of temperature and volume fraction on the viscosity $\mathrm{Al}_{2} \mathrm{O}_{3}$ nanoparticles dispersed in water, the results reported an increase of $2.9 \%$ in the viscosity of base fluid at a volume fraction of $0.3 \%$ and with the increase in temperature the viscosity of Nano fluid decreases continuously $[15,16]$. The results of Zhou [17] showed that the specific heat of water decreases by $50 \%$, when $\mathrm{Al}_{2} \mathrm{O}_{3}$ nanoparticles were dispersed in a volume fraction range of 0 to $21.7 \%$ [18]. In this paper, the effect of volume fraction, sonication time, settling time, diameter of particles and temperature on the thermal properties of zinc oxide and single walled carbon nanotube based Nano fluid $s$ is presented.

\section{Experimental Procedure}

In order to study the effect of various parameters on thermal properties (Thermal conductivity, viscosity and specific heat) of Nano fluid, zinc oxide $(\mathrm{ZnO})$ nanoparticles and single walled carbon nanotube (SWCNT) has been purchased from Rainste Nano Ventures Pvt. Ltd., Noida. The average diameter of $\mathrm{ZnO}$ powders are $14 \mathrm{~nm}$ and $25 \mathrm{~nm}$ with $1 \mathrm{~nm}$ surfactant coating of oleic acid and of SWCNT is $10 \mathrm{~nm}$. The density of $\mathrm{ZnO}$ nanoparticles and SWCNT is $5600 \mathrm{~kg} /$ $\mathrm{m}^{3}$ and $0.05 \mathrm{~kg} / \mathrm{m}^{3}$ respectively. The as received powders are sealed, dried and loosely agglomerated. The two step method was used to prepare $\mathrm{ZnO}$ based ethylene glycol (EG) Nano fluid s of two different volume fractions; $0.01 \%$ and $0.05 \%$. The relative thermal conductivity and viscosity of EG based $\mathrm{ZnO}$ Nano fluid s are compared with DI water based $\mathrm{ZnO}$ Nano fluid s. The experiments were also carried out with SWCNT as nanoparticles and water as base fluid for a volume fraction of $1 \%$. The thermal conductivity was measured by Decagon devices KD2Pro Thermal Properties Analyzer (Decagon Devices Inc. Pullman, WA, USA). The Viscosity of the sample is measured by the instrument named Brookfield DV III Rheometer (Brookfield DV III Ultra Manual). This rheometer is a cone plate viscometer which is a precise torque meter.

\section{Results and Discussion}

Several measurements were carried out for DI water and ethylene glycol as basefluids, to investigate the effect of sonication time, settling time and temperature on the thermal properties of the Nano fluid. In Figure 1, the relative thermal conductivity of $\mathrm{ZnO}$ Nano fluid s increases for both basefluids ethylene glycol and DI water. The relative thermal conductivity of $\mathrm{ZnO}$ ethylene glycol based Nano fluid s shows low enhancement as compare to DI water based Nano fluid s, because the ethylene glycol has more viscosity due to which $\mathrm{ZnO}$ nanoparticles takes more time to disperse in ethylene glycol basefluids. As a result, surface to volume ratio decreases in ethylene glycol based Nano fluid $s$. In Figure 2, the samples were prepared by dispersing nanoparticles in ultra-bath sonicator up to 8 hours with basefluids ethylene glycol and DI water. The relative thermal conductivity of $\mathrm{ZnO}$ ethylene glycol and DI water based Nano fluid s decreases as the settling time increases because, as time increases the nanoparticles which were dispersed in basefluids, starts agglomerated due to which cluster formed and settle down as the time increases. The decreases rate of relative thermal conductivity in ethylene glycol based Nano fluid $s$ is less as compare to DI water based Nano fluid s because, the viscosity of ethylene glycol is

*Corresponding author: Tushar A Sinha, Department of Mechanical Engineering, Thapar University, Patiala 147004, India, Tel: +91 9592057464; E-mail: honeysinha497@gmail.com

Received October 25, 2014; Accepted November 02, 2014; Published Novembe 10,2014

Citation: Sinha TA, Kumar A, Bhargava N, Mallick SS (2014) An Experimenta Investigation into the Thermal Properties of Nano Fluid. J Appl Mech Eng 4: 148 doi:10.4172/2168-9873.1000148

Copyright: ( 2014 Sinha TA, et al. This is an open-access article distributed unde the terms of the Creative Commons Attribution License, which permits unrestricted use, distribution, and reproduction in any medium, provided the original author and source are credited. 
Citation: Sinha TA, Kumar A, Bhargava N, Mallick SS (2014) An Experimental Investigation into the Thermal Properties of Nano Fluid. J Appl Mech Eng 4: 148. doi:10.4172/2168-9873.1000148

more due to which nanoparticles will not settle down, as in DI water based Nano fluid s (Figures 1 and 2).

Figure 3 shows the relative thermal conductivity of $\mathrm{ZnO}$-ethylene glycol and $\mathrm{ZnO}$-DI water Nano fluid s increases as the temperature increases because with the increase in temperature, Brownian motion of nanoparticles increase which excites the particles due to which random motion of nanoparticles increases and the particles starts strikes with each other and transfer the heat energy. Figure 4 shows that the relative viscosity of EG-ZnO Nano fluid decreases with the increase in sonication time, but increases in the case of water- $\mathrm{ZnO}$ Nano fluid. The viscosity of water based Nano fluid is more than ethylene glycol based Nano fluid. Also with the increase in size and volume fraction of

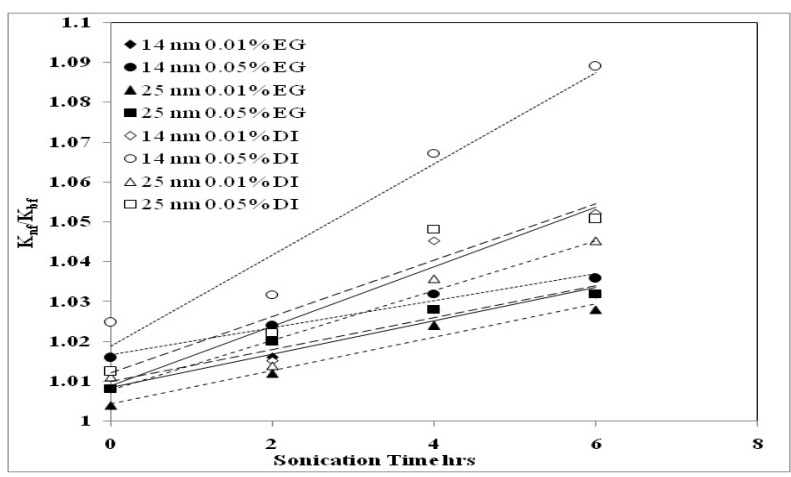

Figure 1: Comparison of relative thermal conductivity with basefluidsEG and DI water versus sonication time.

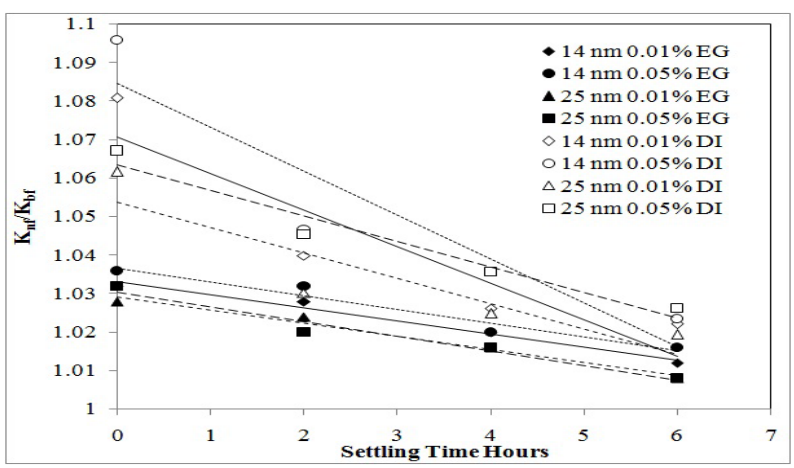

Figure 2: Comparison of relative thermal conductivity with basefluids EG and DI water versus settling time.

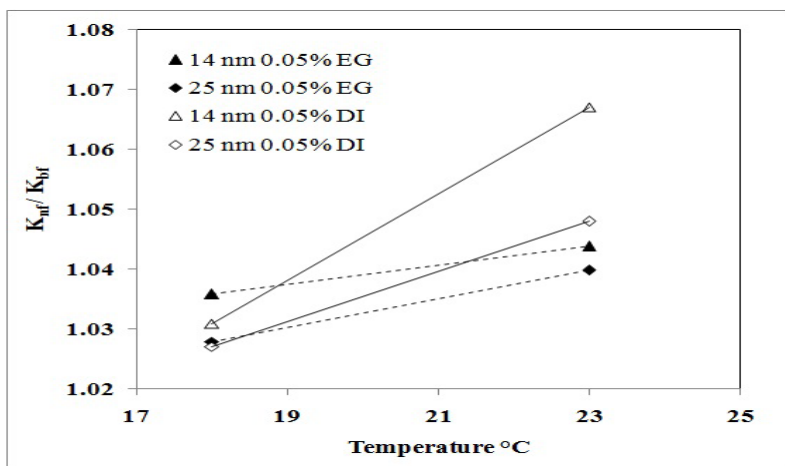

Figure 3: Comparison of relative thermal conductivity with basefluids EG and DI water versus temperature.

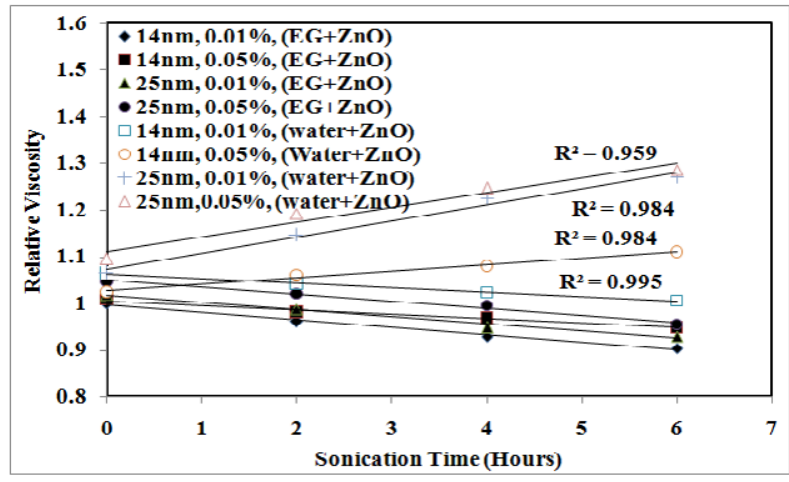

Figure 4: Relative viscosity versus sonication time for EG-ZnO and water$\mathrm{ZnO}$ nanofluid.

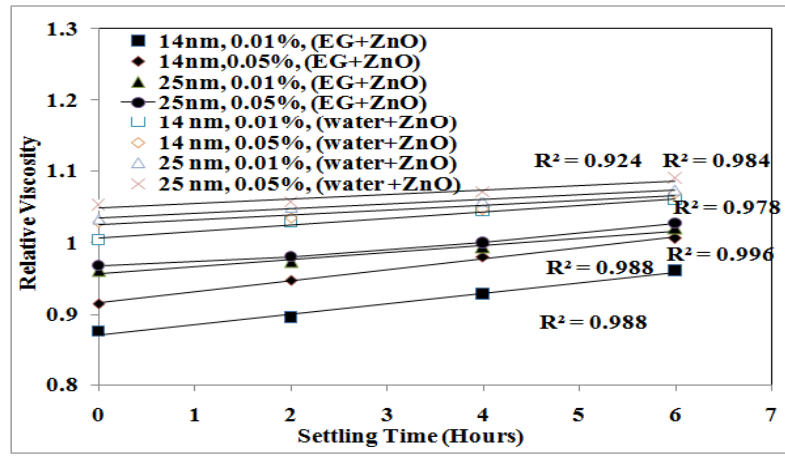

Figure 5: Relative viscosity versus settling time for EG-ZnO and water$\mathrm{ZnO}$ nanofluid.

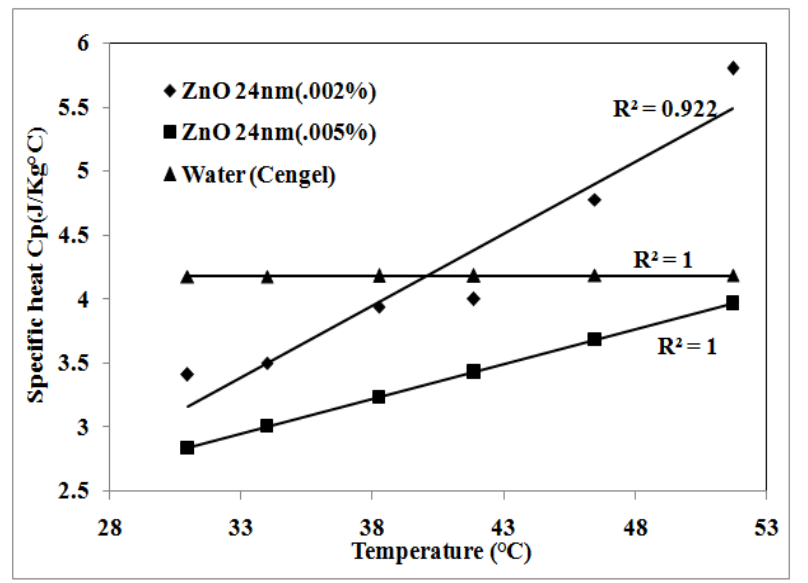

Figure 6: Variation of specific heat of $\mathrm{ZnO}$-water nanofluid with temperature.

nanoparticles in base fluid, the relative viscosity of Nano fluid increases continuously. The relative viscosity of ethylene glycol based Nano fluid comes very close to 1 at zero hours of sonication. In Figure 5, the rate of enhancement in viscosity of EG-ZnO Nano fluid is less as compared to water-ZnO Nano fluid. This is because the particles in Nano fluid start to settle down and agglomerate as the sonication of Nano fluid is stopped. As the viscosity of ethylene glycol is comparatively higher than that of water, which makes the particles suspended for a longer time due to which, there is less increase in the viscosity of ethylene 
Citation: Sinha TA, Kumar A, Bhargava N, Mallick SS (2014) An Experimental Investigation into the Thermal Properties of Nano Fluid. J Appl Mech Eng 4: 148. doi:10.4172/2168-9873.1000148

glycol based Nano fluid (Figures 3-5).

In Figures 6 and 7, the variation of specific heat of $14 \mathrm{~nm}$ and $25 \mathrm{~nm}$ sized $\mathrm{ZnO}$-water Nano fluid with temperature is shown. The specific heat of Nano fluid is found to be increasing with the increase in temperature for a range of $30^{\circ}$ to $50^{\circ} \mathrm{C}$. But the specific heat of water remains unchanged [11] for the specified range (Figures 6 and 7).

In Figures 8 and 9, the relative thermal conductivity of SWCNT - water Nano fluid increases with the increase in sonication time and decreases with the increase in settling time. In Figures 10 and 11, the viscosity of Nano fluid is decreasing with the increase in sonication time and increases with the increase in settling time. Also with the increase in power of sonication, the conductivity of Nano fluid is increasing and viscosity of Nano fluid is decreasing (Figures 8-11).

\section{Conclusion}

The results of the current investigation clearly indicate that the thermal conductivity of Nano fluid increases with the increase in the sonication time, but the viscosity of Nano fluid decreases with it. Also with the increase in settling time, the thermal conductivity decreases and viscosity increases. With the increase in temperature, the thermal

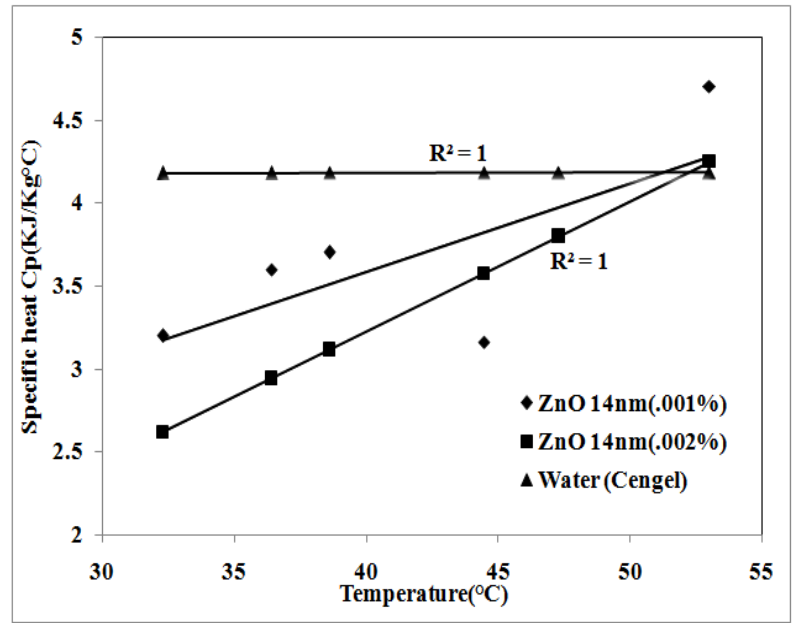

Figure 7: Variation of specific heat of $\mathrm{ZnO}$-water $(14 \mathrm{~nm})$ with temperature.

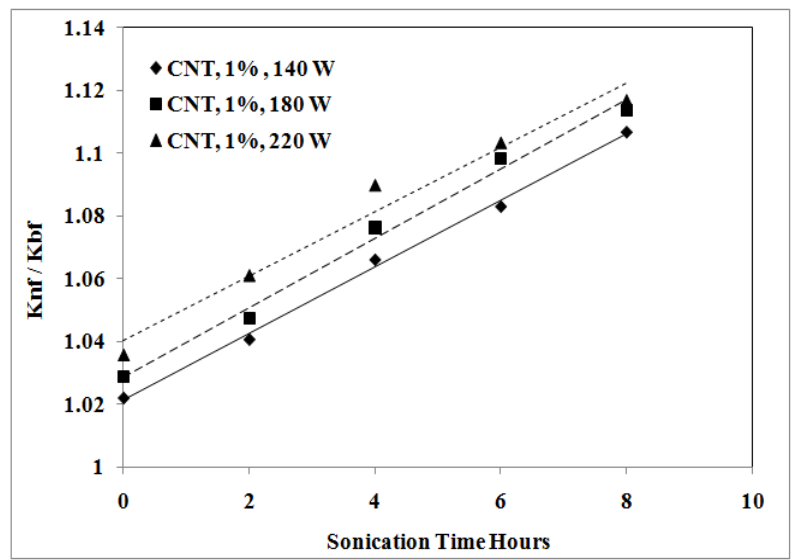

Figure 8: Thermal conductivity ratio variation with sonication time at different sonication power.

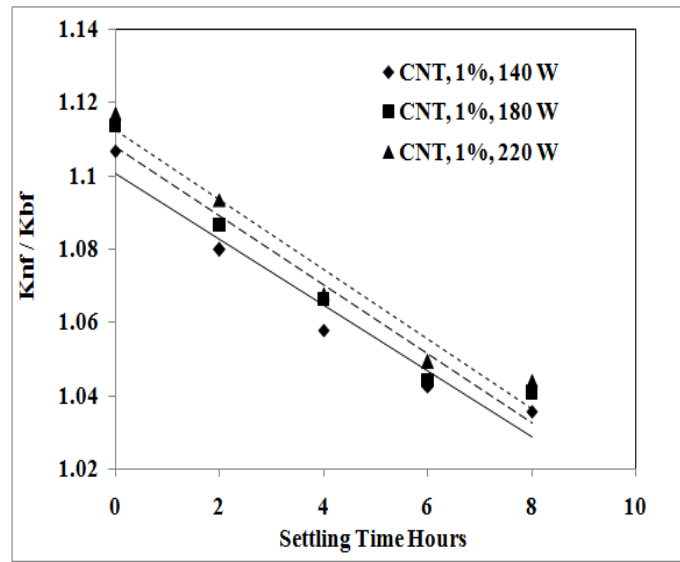

Figure 9: Thermal conductivity ratio variation with settling time at different sonication power.

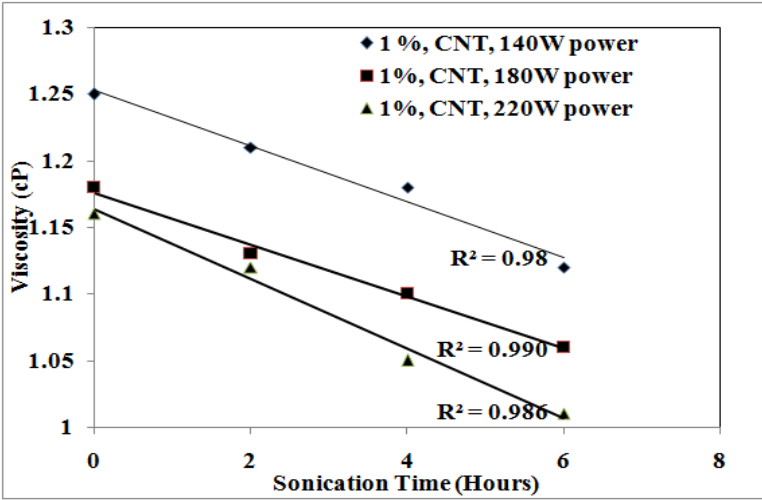

Figure 10: Variation of viscosity of water based single walled carbon nanotube nanofluids with sonication time.

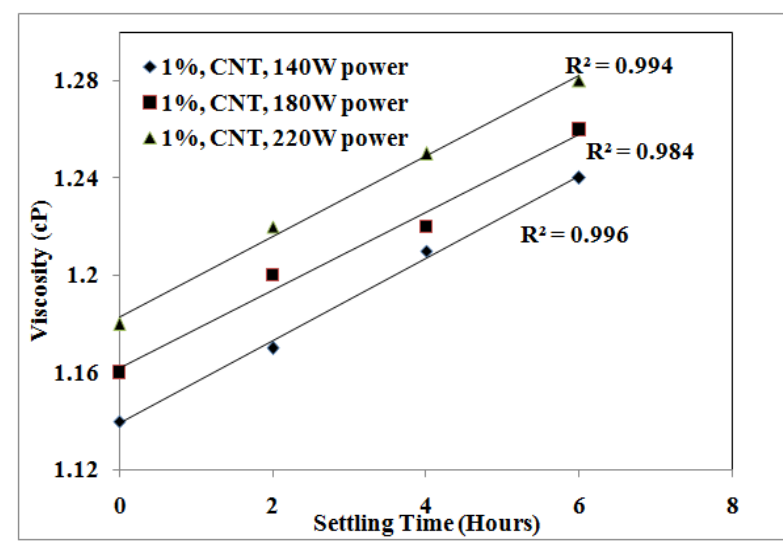

Figure 11: Variation of viscosity of water based single walled carbon nanotube nanofluid with settling time.

conductivity and specific heat of Nano fluid increases and viscosity decreases.

\section{Acknowledgement}

Thapar University-Seed Money Grant (Financial Assistance). 
Citation: Sinha TA, Kumar A, Bhargava N, Mallick SS (2014) An Experimental Investigation into the Thermal Properties of Nano Fluid. J Appl Mech Eng 4: 148. doi:10.4172/2168-9873.1000148

Page 4 of 4

\section{Nomenclature}

$\mathrm{K}=$ Thermal conductivity

DI=Deionized

$\mathrm{nf}=$ nano fluid

$\mathrm{bf}=$ base fluid

\section{References}

1. Choi SUS, JA Eastman (1995) Enhancing thermal conductivity of fluids with nanoparticles, in Developments and Applications of Non-Newtonian Flows, D. A. Singer and H. P. Wang, Eds., American Society of Mechanical Engineers, New York, 99-105.

2. Mintsa HA, Roy G, Nguyen CT, Doucet D (2009) New temperature dependent thermal conductivity data for water-based nanofluids. International Journal of Thermal Sciences 48: 363-371.

3. Jang SP, Hwang KS, Lee JH, Kim JH, Lee BH, et al. (2007) Effective Thermal Conductivities and Viscosities of Water-based Nano fluids Containing $\mathrm{Al}_{2} \mathrm{O}_{3}$ with Low Concentration, International Conference on Nanotechnology, August 2-5, 2007, Hong Kong.

4. Nguyen CT, Desgranges F, Roy G, Galanis N, Mare T, et al. (2007) Temperature and particle-size dependent viscosity data for water-based nanofluids-Hysteresis phenomenon. International Journal of Heat and Fluid Flow 28: 1492-1506.

5. Shin D, Banerjee D (2011) Enhanced Specific Heat of Silica Nanofluid. Journal of Heat Transfer 133

6. Kwak K, Kim C (2005) Viscosity and thermal conductivity of copper oxide nanofluid dispersed in ethylene glycol. Korea-Australia Rheology Journal 17: 35-40.

7. Yu W, Xie H (2012) A Review on Nanofluids: Preparation, Stability Mechanisms and Applications. Journal of Nanomaterials 2012.
8. Buongiorno J (2006) Convective transport in nanofluids. ASME J Heat Transfer 128: $240-250$.

9. Das SK, Choi SUS, Yu W, Pradeep T (2007) Nanofluids: Science and Technology. Wiley, New Jersey.

10. Wong KV, Leon OD (2010) Applications of nanofluids: current and future. Adv Mech Eng.

11. Wen D, Lin G, Vafaei S, Zhang K (2011) Review of nanofluids for heat transfer applications. Particuology. 7: 141-150.

12. Calvin H Li, Peterson GP (2006) Experimental investigation of temperature and volume fraction variations on the effective thermal conductivity of nanoparticle suspensions (nanofluids). J Appl Phys 99.

13. Kakaç S, Pramuanjaroenkij A (2009) Review of convective heat transfer enhancement with nanofluids. Int J Heat Mass Transfer 52: 3187-3196.

14. Jang SP, Hwang KS, Lee JH, Kim JH, Lee BH, et al. (2007) Effective Thermal Conductivities and Viscosities of Water-based Nanofluids Containing $\mathrm{Al}_{2} \mathrm{O}_{3}$ with Low Concentration, International Conference on Nanotechnology, August 2-5, 2007, Hong Kong.

15. Saidur R, Leong KY, Mohammad HA (2011) A review on applications and challenges of nanofluids. Renewable and Sustainable Energy Reviews 15: 1646-1668.

16. Mahian O, Kianifar A, Kalogirou SA, Pop I, Wongwises S (2013) A review of the applications of nanofluids in solar energy. Int $\mathrm{J}$ Heat Mass Transfer 57: 582-594.

17. Zhou SQ, Ni R (2008) Measurement of the Specific Heat Capacity of WaterBased $\mathrm{Al}_{2} \mathrm{O}_{3}$ Nanofluid. Appl Phys Lett 92.

18. Cengal YA (2007) Heat and Mass Transfer, A Practical Approach; Tata Mcgraw Hill Publication. 